NOTAS

\title{
LA EDUCACIÓN COMO VIDA, ARTE, POESÍA, LIBERTAD Y CREACIÓN
}

Carlos de la Isla*

La persona indicada para presentar la excelente obra de Joaquín Xirau debe ser filósofo que sepa apreciar la inmensa calidad de su cosmovisión; debe ser un gran pedagogo, educador que valore con propiedad los conceptos educativos de su magna obra; debe ser historiador capaz de juzgar tiempos, espacios y dimensiones de su historia de la filosofía; debe ser poeta que sepa apreciar con la más fina sensibilidad estética los símbolos, mitos y metáforas de su lenguaje singular, y además, debe pertenecer como rama cercana al tronco del árbol genealógico de la familia Xirau para que sepa apreciar las virtudes de la paternidad, de la ejemplaridad y de la más recia calidad familiar de la singular personalidad de Don Joaquín Xirau.

* Departamento Académico de Estudios Generales, ITAM.
Esa persona, la única persona indicada, distinguido filósofo, muy apreciado maestro, preciso historiador, excelente poeta y extensión genética y espiritual de Don Joaquín Xirau es, por supuesto su amado hijo Ramón Xirau con cuya presencia nos sentimos muy honrados. Sólo él tiene el concepto preciso y la palabra adecuada para presentar la obra admirada de su Señor padre.

Después de Don Ramón, con algunos atributos semejantes y por sus inconmensurables lectura, análisis, meditación y hasta devoción por la obra de Don Joaquín, ciertamente la persona más indicada para esta presentación es la distinguida y muy querida maestra Gabriela Hernández García. Ella ha realizado un cuidadosísimo trabajo de investigación, de exégesis y hasta de hermenéutica que le despertó el entusiasmo hasta la pasión por el pensamiento de Joa- 
NOTAS

quín Xirau. Prueba evidente es su excelente libro titulado: "La plenitud vital. Ética de la conciencia amorosa en la filosofía de Joaquín Xirau”.

Junto a estos dos brillantes personajes todos los demás estamos en un plano de admiración reflexiva. Espero que mis colegas no se sientan incómodos con la jerarquía expresada.

Por mi parte, y desde mi reflexión admirativa, emplearé mi porción de tiempo más en expresar el pensamiento textual de Don Joaquín que en mis apreciaciones personales.

En la difícil, pero obligada selección he elegido la obra referida a la educación por inclinación personal, por las fuertes y urgentes lecciones que aporta sobre la esencia misma de la educación, sobre los educadores y métodos, sobre la cultura y la ciencia, sobre los vicios y deberes del quehacer universitario.

Me voy a referir especialmente a los escritos contenidos en el Tomo II de las Obras Completas: Estudios sobre educación y sobre el humanismo hispánico.

Joaquín Xirau percibe la educación como una expresión orgánica del maravilloso misterio de la vida. La acción educadora es una acción que vivifica. Y como la vida no puede ser considerada unilateral y aislada, la educación es el centro del que surgen y al que convergen todos los hilos vivos de la realidad plenaria.

\section{Manuel B. Cossío y la educación en España*}

\section{El educando}

Si el problema de la educación se reduce a un aspecto del problema radical de la vida, dondequiera que aparezca la vida es preciso admitir la posibilidad de un proceso educador (p. 103).

El individuo se sitúa en el centro del mundo y por lo tanto, de la acción educadora (idem).

La obra de la educación no es, ni puede ser, unilateral y exclusiva. En ella convergen todos los círculos. El individuo no es una realidad separada. Se nutre de su contorno entero y en él y por él se eleva a la plena conciencia de su destino. La educación es una realidad universal en la cual convergen y de la cual parten todos rayos que conducen a todos los ámbitos de la realidad orgánica, compleja y plenaria. Sólo en el organismo y la armónica cooperación de todas las esferas sociales es posible llegar a la realización de una educación perfecta. Cualquier amputación es

* Título del libro del cual han sido extraídos los fragmentos aquí citados, publicado originalmente en 1944. 
NOTAS

una deformación monstruosa (p. y el tacto que conducen al maestro a 104).

la necesaria humillación que lo con-

(...) La educación consiste, en lo vierte en discípulo para entender esencial, en capacitar, es decir, en dar poderes para la vida, vivificar (...). (p.106).

No es lo que importa formar la vida para un ideal, sino dar a la vida la forma ideal en que consiste su propia esencia. Sólo así el tiempo se impregna de eternidad (p.107).

Por eso para realizar esa obra prodigiosa que da a la vida la forma ideal se hace necesario un hombre excepcional, el educador.

\section{El educador}

Es el educador un ser consciente, en posesión de un pleno conocimiento de la tarea a realizar. Para ello necesita vocación, es decir, amor, conocimiento, es decir, ciencia, luz y voluntad o determinación resuelta de obrar de acuerdo con la aptitud que le ha sido otorgada. Tales son las condiciones esenciales de todo verdadero maestro (p. 104).

Para Joaquín Xirau la ley suprema de la educación es atender a cada educando de acuerdo a su ser personal único y original por su naturaleza, para lo que son necesarios el amor

herencia Joaquín Xirau se pregunta:

\section{El método}

¿Cómo realizar la tarea educativa? ¿Cómo llegar a capacitar, a otorgar los poderes necesarios para que la vida se realice? Vivificando, sin duda alguna, alimentando y nutriendo las fuentes originarias de la vida (p. 108).

La educación y la vida en que se funda es tránsito constante de lo virtual y recóndito a lo actual y luminoso. No es lo ideal un esquema previo, muerto y petrificado. Cada cual lleva en sí implícita una idea, una ley inmanente que brota de las raíces profundas de su vida personal: La libertad no nos es dada. Es preciso conquistarla mediante la conquista de la propia personalidad (...). La educación no puede ser otra cosa que el desarrollo armónico de la propia ley personal, inmanente e intransferible (p. 109). Siendo cada educando un caso, un individuo peculiar y distinto, cada caso pide su método, puesto que cada uno posee su propia idiosincrasia y su propia ley. Ley suprema de la educación es tratar a 
cada educando de acuerdo a las características propias de su individualidad.

De allí la necesidad de que el educador posea amor y tacto para adecuar su propia individualidad a la personalidad del individuo que tiene a su cargo. Si esto falta todo el resto sobra. La obra entera de la educación cae por su base (p. 114).

Y cuando Don Joaquín Xirau señala el método, el camino de la educación, exalta el trabajo gozoso, el sentido del juego, la escuela, lugar de goce y la cultura como arte, poesía, libertad, creación.

Es preciso buscar una forma de trabajo cuya finalidad reside en sí mismo. El trabajo más gozoso es aquel cuya finalidad sea el goce íntimo del trabajo mismo, un trabajo sin producto externo y que produzca goce (...) tal es el sentido del juego.

Jugar es realizar una actividad por el puro goce desinteresado de la misma. La escuela es y debe ser un lugar de goce (...) nada más opuesto a la educación que la imposición de tareas ajenas al interés desinteresado que surge del libre empleo de las fuerzas de la propia vitalidad (p. 118).
La cultura, en sus más altas esferas es producto del trabajo desinteresado, del libre juego de las fuerzas espirituales. Ya Schiller adivina la relación entre el arte y el juego. El arte es un juego, el juego por excelencia. El juego es la primera poesía de la vida. Y toda cultura es, esencialmente, arte, poesía, libre creación espiritual.

Desde esta perspectiva de las relaciones totales, de la cultura en sus más altas esferas, es muy comprensible el enérgico rechazo de Joaquín Xirau al especialismo; convivencia en una misma persona del más vasto saber y de la más radical ignorancia: fenómeno del "nuevo bárbaro, -en expresión de Ortega y Gasset- que sabe mucho de una sola cosa e ignora de raíz todo lo demás”.

(...) Uno de los problemas más graves de la pedagogía contemporánea es el problema de la especialización. Del exceso de especialización sufren actualmente, las universidades y las escuelas. La sociedad entera se siente dispersa, dislocada, rota. La separación de las especialidades tiende a sumir la especialización en la barbarie (...). En esto, como en todo, la obra educadora sufre las consecuencias de una abstracción inmoderada. No se tiene bastante en cuenta la exis- 
NOTAS

tencia de una realidad orgánica y concreta a la cual es preciso referirlo todo. La totalidad abstracta conduce a la vacuidad. La especialización unilateral, a la mecanización y a la pérdida del sentido y del valor. Nada tiene sentido por sí mismo. Todo es miembro de un organismo plenario al servicio del cual está y del cual recibe la savia. Quien pretende saber una sola cosa ni tan siquiera sabe aquello mismo que tiene la pretensión de saber. En fórmula sintética: sólo es posible llegar a una solución eficaz mediante el cultivo de la totalidad de los intereses referidos a un interés central y predominante. La vocación y la aptitud se destacan sobre el marco de una personalidad humana. Es un interés particular, pero es el interés de un hombre. Si lo separamos del fondo sobre el cual se destaca queda disecado y muerto. El interés unilateral desemboca necesariamente en el vacío del tedio. Es preciso formar un hombre abierto a todos los ámbitos del interés humano, en la vida y en el mundo. Pero cada hombre debe considerar al mundo desde el punto de vista que le es peculiar. No es posible contemplar un paisaje desde cualquier parte. Para contemplarlo entero es preciso escoger un punto de vista. Sólo así adquiere el mundo el sentido de su realidad plenaria y deja de ser una abstracción vacía. Para consagrarse a una sola cosa es preciso consagrarse a todas y tener el espíritu abierto a los cuatro vientos del universo. Tal es el único sentido que puede tener el humanismo en el orden de la vida personal y en el de la vida colectiva.

Una de las percepciones más lúcidas y brillantes de Joaquín Xirau es sin duda la que expresa el sentido de la universidad. Su pensamiento es diáfano, pero también apasionado cuando fustiga los vicios del oportunismo, del mercantilismo, del especialismo que tratan de imponer los mercaderes: Defiende a su querida Universidad de sus agresores como sólo un dignísimo universitario puede hacerlo.

\section{Sentido de la Universidad}

Fácil es hoy darse cuenta de que la desorientación de la vida universitaria es causa y efecto al propio tiempo de la quiebra profunda que socava en lo más hondo las raíces de nuestra cultura occidental (p. 468).

Si la universidad es mala -como ha ocurrido con harta frecuencia entre nosotros- los profesores cifran su aspiración en el hecho 
NOTAS

de ocupar un cargo oficial que cubre menguadamente una parte de sus necesidades perentorias y otorga ciertas ventajas y honores sociales; los discípulos tratan de pasar rápidamente y como Dios les da a entender una serie innumerable de pruebas, más o menos difíciles y fastidiosas, saltando como sobre ascuas, por encima de una serie de artificiosos obstáculos diestramente interpuestos en la libre carrera de su carrera libre (p. 469).

Si de veras queremos tener una universidad es preciso de una vez abandonar todo gesto de hueca retórica, todo vago deseo informado, tratar de decir con precisión qué es lo que queremos y poner con eficacia todos los medios indispensables para llegar a la consecución de nuestra idea, en la seguridad de que toda idea, claramente concebida y honradamente anhelada, acaba por convertirse en realidad (p. 470).

Los miembros de la universidad son o deben ser personas cultas. Profesión, ciencia, cultura: he ahí las tres funciones que la conciencia común atribuye a los centros universitarios (idem).

No es menos vibrante el estilo de Don Joaquín cuando señala los grandes compromisos de la Universidad, con la ciencia como sendero sin fin, con los maestros que no son los que más saben sino los que más ignoran, con los estudiantes por la perplejidad del mayor saber que añade ignorancia, con la teoría que da luz y dirección a la práctica.

\section{Ciencia}

¿Cuál es la función científica de la universidad en los tiempos actuales? ¿O es que la ciencia ha dejado de ser uno de sus designios esenciales, acaso su función por excelencia? Lo cierto es que, a pesar de sus desviaciones temporales la aspiración científica se ha hallado siempre vinculada a las tareas universitarias. Es más, si hay una función específicamente reservada a la institución universitaria, ésta es la actividad científica. La universidad es la corporación por y para la ciencia (p. 474). No es la ciencia primordialmente posesión. Lo alcanzado es un punto de apoyo, trampolín para saltar más allá. El tesoro se trueca en equipaje, el equipaje en provisión. Nadie como ella puede hacer suya la frase admonitoria de Don Quijote: "en verdad Sancho amigo que es mejor el camino que la posada”. La ciencia es camino, no po- 
NOTAS

sada, método, descubrimiento, horizonte, sendero (...).

Siendo esto así cambia la fisonomía del discípulo y del maestro. No es ya el maestro el que se halla en posesión de la verdad ni es la ignorancia la característica peculiar del discípulo. De lo uno -el saber ordinario- ambos saben cuánto necesitan. En lo otro -en el saber científico- ambos tienen que medir la pequeñez de lo que saben con la inmensidad de lo que ignoran. Y mayor es el volumen de su ignorancia cuanto más avanzados se hallen en la trayectoria de su camino (...).

Quien añade saber añade ignorancia. No es el maestro quien más sabe sino precisamente quien ignora más, quien es capaz de adquirir clara conciencia de la magnitud de su ignorancia y de despertar en el discípulo la evidencia de esta verdad primordial. Iniciar en las ciencias es iniciar en las almas jóvenes el estado de inquietud indispensable para que se den cuenta de lo que con más urgencia importa saber: que en la ciencia no les será dado nada de modo gratuito, que cuanto quieran tener lo tendrán que conquistar y que el único saber auténtico es el saber íntimo, personal (p. 478).

\section{Profesión}

La inmensa mayoría de los miembros de la universidad no son ni van a ser hombres de ciencia (p. 480).

Si nos preguntamos cuáles son las profesiones que necesariamente deben formarse en el seno de la universidad no parece que la respuesta ofrezca, en principio, dificultad alguna. Prescindiendo de razones empíricas y circunstanciales que varían de lugar en lugar y pueden aconsejar soluciones locales diversas, creo que estamos autorizados para decir que universitarias son todas las profesiones cuyo ejercicio se halla de un modo directo bajo la dependencia de la formación científica y se nutre de los resultados de la ciencia (p. 486).

La práctica sin la teoría es ciega, podríamos decir, parafraseando a Kant; la teoría sin práctica es vacía. De allí la falla gravísima de la generalmente denominada enseñanza teórica. Su defecto no es que lo sea. Es precisamente que no lo es. La enseñanza universitaria debe ser teórica y cuanto más mejor. Pero es preciso que lo sea de veras. La teoría es el título de nobleza de la práctica. Si no es 
esto se reduce a puro verbalismo insustancial.

Teoría y práctica deben partir juntas y seguir juntas a todo lo largo de la jornada. No es posible pensar nada substancial sobre nada si no se piensa sobre una actividad real. Lo primero para hacer cualquier cosa es echar a andar, realizar, hacer (483).

En el subtítulo Educación y Cultura Joaquín Xirau enumera muchas actividades y virtudes académicas que parecerían una completa descripción de una distinguida universidad, sin embargo, afirma que mientras no se dé la perfecta coordinación de todas las esferas de las ciencias y de la cultura la universidad no habrá cumplido su misión.

\section{Educación y cultura}

Una institución capaz de organizar con la posible perfección el desarrollo de las actividades científicas, de formar a la juventud en la disciplina y los métodos de investigación y la especulación, de contribuir con sus descubrimientos al acervo del saber humano y de formar en torno a ello equipos bien dotados de personas capaces de intervenir con eficacia y competencia, de organizar, construir, modificar, perfeccionar y elevar el nivel de cada una de las esferas de las actividades humanas, no sería todavía acreedora al título de universidad (487).

La trituración mecánica de las actividades tiende hoy a disolver en el hombre su calidad de persona humana y a convertirlo en una pieza, ajustada de una mecanismo anónimo.

El cuerpo de la universidad se trueca así en un organismo descuartizado, aún sin salir del seno de las actividades intelectuales, y el desarrollo de las ciencias se resiente de esa radical dislocación. Así resulta que la ciencia puede existir acaso en sí misma y por sí misma-dado que esta afirmación puede alcanzar algún sentido coherente. No existe para nadie y en la mente de nadie. ¿ No hay el peligro de que aquella entidad casi incógnita (la ciencia) se convierta en un mito desorbitado? (488). Las ciencias en sí mismas, y las actividades prácticas que de ellas derivan sólo tienen sentido si se hallan en estrecha y precisa conexión y no es posible saber de las unas sin tener una clara y sólida idea de todas y cada una de las demás (idem).

Con la mayor frecuencia y desde los más diversos puntos de vista se ha destacado el hecho curioso 
NOTAS

e insólito de la convivencia en la misma persona de la más alta sabiduría en una rama del saber y la más radical ignorancia en lo relevante a los intereses integrados de la vida humana. Una refinada especialización puede coincidir y coincide con frecuencia con una desoladora incultura. Un físico eminente me preguntaba un día con aire de doctoral suficiencia para qué servía el derecho -dando por supuesto naturalmente que no servía para nada (489).

Los miembros de la civilización actual andan sueltos y desquiciados. La universidad se ha mostrado hasta ahora incapaz de reaccionar con eficacia ante la inminencia del peligro.

Vive ella misma dispersa y descuartizada, multiplica sin cesar el mínimo de sus escuelas y departamentos en una proliferación suicida (...). ¿Es posible que se inicie en su seno un movimiento que tienda a salvarla y a salvar la cultura entera de la desintegración que la amenaza? Sería insensato pensar que la universidad por sí sola pueda algún día poseer el poder soberano capaz de reintegrar al mundo su sentido. Puede, sin embargo cooperar a ello y aún alcanzar una función eminente en esta tarea de reconstrucción (490).
En qué consiste la cultura, general o si se quiere mejor, ¿¿cuál es en general el sentido de la cultura? No puede residir en la posesión de una determinada cantidad de saber. Es posible alcanzar conocimientos muy considerables de física, matemática, medicina, derecho ... y ser en lo demás un perfecto palurdo (idem).

¡Qué digna y trascendente es la visión de Joaquín Xirau sobre la Universidad!

¡Cómo enfatiza su necesaria aspiración de humanidad, su elevación a lo ideal, su reflexión de alto estilo sobre su mundo y su historia!

Las funciones particulares y específicas de la universidad requieren y reclaman un sentido muy alto. Es la aspiración del hombre en su pura y auténtica humanidad. El hombre en su realidad individual y en su peregrinación colectiva a través de la historia quiere elevarse por encima de sí mismo y aureola su vida con el halo de lo ideal (491).

Preciso es que la universidad y cada uno de sus miembros adquieran clara conciencia de su posición ante el mundo y ante la historia: Si ella es precaria, de la dificultad misma surgirán las fuerzas necesarias de recuperación. 
(...) En toda universidad digna de tal nombre es preciso que se realice una reflexión de alto estilo sobre la totalidad de la vida humana y que en ella participen con ahínco la totalidad de sus miembros.

(...) Esto es la cultura, el cultivo de lo humano, la única cultura posible. Reflexión crítica sobre la situación y el destino del hombre. Espíritu despierto y vigilante (494).

El espléndido sentido de la universidad, la educación como proceso vivificador que da a la vida la forma ideal, que se realiza en un trabajo gozoso, que es arte, poesía y creación, crecimiento personal pleno, compromiso con la sociedad y con la propia historia. ¡Qué concepción tan diferente a la educación mercantil del adiestramiento funcional para ser útiles y obtener buen precio como mercancías en la compra-venta de personas y de cosas del mercado!

Es excelente la concepción de Joaquín Xirau sobre la educación y sobre la universidad pero también es excelente toda su cosmovisión que constituye una verdadera riqueza del pensamiento universal.

Felicito una vez más la magnífica labor en especial del Dr. Don Ramón Xirau y de la muy distinguida Mtra. Gabriela Hernández, quienes hicieron realidad la edición de las Obras Com- pletas de ese hombre excepcional que fue Don Joaquín Xirau y Palau. 